In attempting to estimate correctly the amount of energy used for the actual forward progression of the body it is essential to deduct from the total measured energy output a fraction which will represent what may be termed the basal maintenance metabolism, and it is somewhat difficult to decide what value to take for this purpose. The authors on the whole prefer to take as this basis the energy output found when the subject is standing still with the muscles relaxed, and this value certainly appears more reasonable than that found when the subject is lying at rest, though the latter has been used frequently by earlier workers on the subject. They have, however, considered other possible bases, especially with reference to walking at a very fast pace when pronounced movements of the arms occur.

With one of the subjects the pace was limited to slightly under three miles an hour, but with the other it was varied widely, ranging, roughly, from two and a half to five and a half miles an hour. As the pace increases the amount of energy output to move one kilo of the body weight one metre horizontally increases very greatly, as other observers have found.

Some experiments performed with the subject running showed that it was more economical of energy to run than to walls at the rate of more than five miles an hour.

In examining the influence of food on the energy output during the exercise, the authors find that the increase in the metabolism due to the walking is at any given pace in the main constant and merely superimposed on the increased resting metabolism due to the food. With a large protein diet there is evidence that the heat output per unit of work is increased. Apart from the question of the absolute expenditure of energy, the figures in the various tables will be of extreme interest to any who wish to study the character of the metabolism during muscular exertion.

\section{G. D.}

\section{THE GRAVELS OF EAST ANGLIA.}

THE Cambridge University Press has published two interesting geological pamphlets by Prof. T. McKenny Hughes, the first on "The Gravels of East Anglia" (price Is.), the second entitled "Notes on the Fenland," with a description of the Shippea man by Prof. A. Macalister (price 6d.). The gravels of East Anglia are especially useful in any inquiry as to the age and origin of the superficial deposits of our country, because of their wide distribution and the long continuous sections on the coast, in which many of them may be studied. They consist for the most part of subangular flints, which cannot have been derived directly from the chalk, and Prof. Hughes concludes that they are the débris of an old Miocene land-surface on which the chalk with flints was exposed. After a well-illustrated account of many sections, and a brief discussion of the mammalian remains found in the gravels and associated deposits, Prof. Hughes summarises the sequence of phases in the later geological history of East Anglia as he now understands them. All these gravels are of Pleistocene age, but the marsh-deposits of the fenland are distinctly later. They contain remains of the brown bear and the beaver, which survived in England until historic times, but none of the typical Pleistocene mammalia; while the most remarkable of the birds is the pelican. There is no definite chronological succession which will hold throughout the fens, and the relative dates of the various remains found in them cannot be well determined. The human skull and associated remains from Shippea Hill, described by Prof. Macalister, may be quite modern, though perhaps as old as the Bronze age.

NO. 2438 , VOL. 97$]$

\section{THE ORGANISATION OF INDUSTRIAL SCIENTIFIC RESEARCH.1}

\section{II.}

I $\mathrm{T}$ is the common opinion of those who have to deal with the organisation of research that only a small percentage of all the investigations started are likely to be successful, the great majority being either dropped before they come to an end, or, being carried through, are filed simply as records, without any results having been obtained which would justify the expense of the investigation; that is to say, industrial research is justified only by the great value of the successful attempts, and these must bear the burden of a great number of unsuccessful attempts, which may have been quite as costly as the successful ones themselves. Naturally, the object of organisation is to attempt to reduce the proportion of unsuccessful investigations which will be undertaken, as has already been shown. This can be done by increasing the size of the laboratory, by increasing the specialisation of the workers, and especially by increasing co-operation between workers in different fields.

Naturally, the most important step which could be taken to increase the efficiency of industrial research would be to increase the likelihood of correct choice of a promising investigation, but, unfortunately, very little can be done in this direction. Those with the most experience in research work are all agreed that it is almost impossible to say whether a given investigation will prove remunerative or not. The only general conclusion that can be drawn is that the deeper a given investigation goes towards the fundamentals of the problem the more likelihood there is that the results will be of value, and the more superficial an investigation is, even although it appears more promising at first sight, the less likelihood there is that it will finally prove of real worth, so that the choice of investigations must necessarily be made largely at random, and will be influenced to a great extent by the ideas of the scientific workers themselves; if any worker has a desire to take up any particular line of work, provided that it is associated with the general trend of work in the laboratory, it is usually wise to let him do so, but the expedition with which a decision can be reached as to the probable value of the investigation after it has been started is very greatly enhanced by the complete co-operation of workers in the different branches of science in consultation on the problem.

At this point it might be well to discuss the organisa. tion of a large research laboratory. Such a laboratory should be established in charge of a director who has had some actual manufacturing experience in the works processes, but at the same time he must have a considerable sympathy with purely scientific work and an interest in the advancement of scientific theory. Both these qualifications are desirable, but if such a director combining the two cannot be found, then a man of full scientific training should be chosen and put into a position of responsibility in the manufacturing side of the industry until he has become fully acquainted with the technique of the industry. It is most inadvisable to take a man from the industry who has not had a full scientific training, including advanced research work in academic problems, since he will generally be lacking in sufficient knowledge of, and sympathy with. the more academic investigations of which he will be in charge, and if the two necessary qualifications cannot be found united in one man, it will be necessary to take a man with the scientific

1 An address delivered at Columbia University by Dr. C. E. Kenneth Mees, director of the Research Laboratory, Eastman Kodak Co. Rochester N.X. Continued from p. $4^{1} 3$. 